\title{
As populações caiçaras e o mito do bom selvagem: a necessidade de uma nova abordagem interdisciplinar ${ }^{1}$
}

\author{
Cristina Adams \\ Doutoranda do Departamento de Ecologia - USP \\ Não há extensão plana despovoada, mesmo na mais agitada linha \\ dos costões voltados para o mar alto...As paredes brancas das \\ casas, alinhadas geralmente com a frente para o mar, destacando-se \\ do verde escuro das árvores agrupadas ao redor e refletindo-se em \\ dias ensolarados na água do mar, eis uma associação inseparável de \\ elementos caracterizadores da orla costeira.
}

(França, 1954: 89-92)

\begin{abstract}
RESUMO: A caracterização, na literatura, das comunidades caiçaras como pescadoras, tradicionais, isoladas, auto-suficientes, primitivas e dotadas de um referencial marítimo é discutida com base numa perspectiva diacrônica. Ressalta-se o papel transformador da chegada do barco a motor e da pesca embarcada para as comunidades caiçaras, que as levou a abandonar total ou parcialmente as atividades agrícolas. Esta mudança é inserida num contexto histórico mais amplo, que considera essa passagem como um dos inúmeros ciclos econômicos pelos quais essas comunidades teriam passado. Criticou-se também a falta de uma abordagem ecológica séria e de uma base empírica confiável na literatura, o que muitas vezes tem levado a considerações na linha do discurso ecológico romântico, que tendem a vincular a imagem dos caiçaras ao mito do "bom selvagem". Argumenta-se que a falta de abordagens multidisciplinares reduz a expressão da riqueza cultural das populações caiçaras.
\end{abstract}

PALAVRAS-CHAVE: caiçaras, antropologia ecológica, populações tradicionais, bom selvagem. 


\section{Caracterização}

O termo caiçara tem origem no vocábulo Tupi-Guarani caá-içara (Sampaio, 1987), que era utilizado para denominar as estacas colocadas em torno das tabas ou aldeias, e o curral feito de galhos de árvores fincados na água para cercar o peixe. Com o passar do tempo, passou a ser o nome dado às palhoças construídas nas praias para abrigar as canoas e os apetrechos dos pescadores e, mais tarde, para identificar o morador de Cananéia (Fundação SOS Mata AtLÂNTICA, 1992). Posteriormente, passou a ser o nome dado a todos os indivíduos e comunidades do litoral dos Estados do Paraná, São Paulo e Rio de Janeiro (Diegues, 1988).

Por muito tempo, após o descobrimento do Brasil, o litoral foi quase a única área de povoamento. Apesar de sua grande extensão, existem elementos culturais e sociais comuns a toda a costa brasileira oriundos, em grande parte, de influências semelhantes na sedimentação das bases sócio-culturais dos habitantes do litoral. Nos estados das regiões Sul e Sudeste ocorreram ainda duas particularidades: a deserção de sua população à medida que o povoamento avançou para o interior e o não estabelecimento de imigrantes, ficando este litoral privado de influências culturais externas ${ }^{2}$ (Mussolini, 1980; Marcílio, 1986). Os primeiros brasileiros surgiram da miscigenação genética e cultural do colonizador português com o indígena do litoral, ocorrida nas quatro primeiras décadas, a qual formou uma população de mamelucos que rapidamente se multiplicou. Esta protocélula da nação brasileira foi moldada, principalmente, pelo patrimônio milenar de adaptação à floresta tropical dos Tupi-Guarani. A chegada do negro africano, como escravo, pouco contribuiu nesta primeira fase. Entretanto, sua incorporação à ordem social e econômica acabou gerando, posteriormente, um contingente mestiço de índios, brancos e negros, que viria a constituir o povo brasileiro (Ribeiro,1974 apud Ribeiro, 1987).

Essa população mestiça foi aos poucos se espalhando pelo território, estabelecendo variantes sócio-culturais ${ }^{3}$ de acordo com o tipo de exploração econômica e as peculiaridades ecológico-regionais, conformando, no Brasil 
Revista de Antropologia, São Paulo, USP, 2000, v. 43 nº 1.

rural, um conjunto de subculturas a que se costuma denominar de cultura rústica brasileira ${ }^{4}$ (Ribeiro,1974 apud Ribeiro, 1987). Neste contexto, a cultura caipira $^{5}$ formou-se pelo cruzamento do português com o indígena e produziu o mameluco paulista, na qual o caiçara está inserido. O gênero de vida caiçara combina a agricultura de subsistência, baseada na mandioca, com a pesca ${ }^{6}$. Silva (1993: 13) concorda que a cultura caiçara faz parte da cultura caipira, não simplesmente por se constituir numa variação paralela desta, mas "sim, por fazer parte de inúmeros conjuntos... e, sobretudo, se fundamentar num modo de vida que acreditamos ser específico". Pierson \& Teixeira (1947) e Noffs (1988) também consideram o caiçara uma expressão regional do caipira do interior. Outros autores, porém, discordam e acreditam que caiçaras e caipiras possuem identidade própria, com um tipo de vida e uma cultura que lhe são característicos (Luchiari, s.d.). Setti (1985) observou que o habitante de Ubatuba percebe-se como caiçara na medida em que admite ser assim designado, mas não se auto-define como tal.

Historicamente, a formação das comunidades caiçaras só pode ser entendida no contexto da ocupação do litoral brasileiro e dos ciclos econômicos vividos pela região sul/sudeste. $\mathrm{O}$ caráter predominantemente agrícola de nossa colonização fez que as terras férteis, úmidas e quentes das baixadas fossem as mais ocupadas, inclusive graças à facilidade de escoamento dos produtos para o exterior. Formaram-se então aglomerados grandes e médios, ao redor dos quais gravitavam pequenos núcleos, formados graças a condições particulares da costa, que favoreciam sua ocupação, e que enviavam aos núcleos maiores parte de sua pequena produção (farinha de mandioca, peixe e algum café). Muitas vezes, esses pequenos núcleos converteram-se em compartimentos estanques, com pouca comunicação entre si ou com o exterior, em razão da dificuldade de comunicação por terra. Nestes locais desenvolveu-se, em contrapartida à grande agricultura exportadora, uma agricultura de subsistência, que servia inclusive como retaguarda econômica dos grandes engenhos, garantindo a sobrevivência das populações locais (Mussolini, 1980; Dean, 1996). 
Os fatores geográficos tiveram um papel importante na criação de uma grande variedade de densidades de população entre os grupos litorâneos, servindo ora como elemento de atração para a fixação do homem, ora como elemento de repulsão. Estes fatores contribuíram também para a formação da morfologia social, das formas de ocupação do solo e da utilização dos recursos naturais. Nas escarpas montanhosas da Serra do Mar no Estado de São Paulo, por exemplo, a vegetação se mantinha inexpugnável, criando um fator de isolamento, mas as numerosas pequenas baixadas costeiras com solos secos (sem entretanto faltar um curso d'água) criaram condições que justificaram a configuração do estabelecimento dos grupamentos caiçaras do litoral norte da região Sudeste (Mussolini, 1980; França, 1954; Marcílio, 1986). Para Mussolini , o tipo de vida fechada que se desenvolveu no litoral, quase que isolado do mundo de fora em termos de produtos e influências, por causa da falta de poder aquisitivo, resultou em "um aproveitamento intensivo, quase exclusivo e mesmo abusivo dos recursos do meio, criandose, por assim dizer, uma intimidade muito pronunciada entre o homem e seu habitat." (ibid.: 226).

Até o final do século XVIII, o litoral de São Paulo viveu "dias de abastança e prosperidade" (Almeida, 1946: 37), com uma vida comercial intensa para a época, agricultura florescente e o desenvolvimento de pequenas indústrias. Entretanto, a partir de 1787, com a diminuição do comércio no litoral, muitos agricultores abandonaram suas terras, limitaram suas culturas, ou mudaram-se para o planalto. Assim, o padrão de ocupação da costa Sul e Sudeste foi se alterando a partir do século XIX, quando se iniciou um processo de despovoamento e perda de importância econômica, aumentando a quantidade de pequenos núcleos. Aqueles gêneros produzidos pela economia de subsistência, apesar de possuírem pouca significação econômica, passaram a ser os únicos gêneros de exploração local: a farinha de mandioca e a aguardente (França, ibid.; Mussolini, ibid.). França (ibid: 15-6) descreve o litoral de São Paulo ${ }^{7}$, na primeira metade do século XX, estagnado, "sem fontes econômicas próprias, financeiramente deficitário e demograficamente desfalcado", com exceção do porto de Santos e de 
Revista de Antropologia, São Paulo, USP, 2000, v. 43 nº 1.

algumas áreas reduzidas onde se desenvolveu uma economia agrícola (banana e chá, principalmente) e uma incipiente economia de veraneio, em oposição à ocupação do planalto. Para Mussolini, a primeira impressão que se tinha do litoral, era de que "a vida ali foi simplificada em seus elementos culturais e, em comparação com o passado, reduzida a ponto pequeno. Talvez seja este o aspecto que mais cause a impressão de decadência" (1980: 223).

A economia caiçara era caracterizada por uma oposição tanto à economia indígena primitiva, quanto à economia industrial. Seu sistema de produção era organizado para responder, em primeira instância, às necessidades domésticas, mas ainda assim o caiçara prescindia de insumos externos, para os quais precisava gerar um excedente: ferramentas, habitação, vestuário, sal, pólvora, entre outros. Além disso, devia oferecer uma contribuição à sociedade nacional, sob a forma de impostos. Assim raramente a exploração era totalmente auto-suficiente (Marcílio, 1986). A pesca era uma atividade essencialmente masculina, exceto no caso da pesca da tainha, que se constituía numa forma de pesca coletiva (arrasto de praia) de grande importância para as comunidades caiçaras. $O$ peixe era um alimento básico. Em alguns casos eram criadas galinhas e porcos (id., ibid). No Paraná, a troca entre produtos do mar e da roça era comum (Cunha \& Rougeulle, 1989; Langowiski, s.d.). Em alguns locais, como em Bertioga (SP), durante o século XVIII, desenvolveu-se a pesca da baleia. A pesca era muitas vezes complementada pela coleta de caranguejos, ostras, moluscos.

A função da mulher na sociedade caiçara era o da mãe de família, dona de casa, trabalhadora do lar e da roça. Seu papel era muito importante e essencial para a manutenção do grupo doméstico, sua reprodução, produção e sobrevida. Suas tarefas eram bem definidas: preparo do alimento e criação dos filhos. Ao marido estavam destinadas as atividades de caça e pesca, derrubada e queimada, construção dos ranchos de moradia, transporte e comercialização dos excedentes agrícolas, condução das canoas e dos trabalhos da roça, plantio e colheita (nestes casos podia ser ajudado pela mulher e filhos) (Marcílio, ibid.). 
Nas décadas de 1940-50, a conformação do povoado caiçara era de um grupamento desordenado de casas isoladas umas das outras, escondidas entre a folhagem e protegidas do vento pela vegetação da orla da praia. Apesar de a propriedade ser privada, ela não era cercada e as trilhas permitiam o acesso de todos ao espaço caiçara. A praia era o centro da vida caiçara e ponto de articulação com o mundo exterior. O caiçara se distinguia pela praia a cujo grupo pertencia e a solidariedade entre seus membros era importante fator de equilíbrio, mesmo não sendo regulada por nenhuma organização ou instituição. Apesar de a atividade agrícola ser essencialmente individual e familiar, as trocas e empréstimos de produtos, a prestação de serviços e a ajuda nos trabalhos, sob a forma de mutirão, levavam a uma distribuição mais ou menos eqüitativa dos produtos obtidos nas culturas (França, 1954). O sertão ${ }^{8}$ era o espaço do trabalho, onde se encontravam as roças, os bananais e a floresta, de onde se retirava lenha, ervas medicinais e onde se caçava. Em muitas comunidades podiam ser vistos ranchos construídos na praia, que serviam de habitação temporária durante a época de pesca de algumas espécies, como a tainha (Willems, 1946; França, ibid.). A estrutura da casa caiçara tradicionalmente era a mesma do caipira do interior: paredes de pau-a-pique, telhado de sapê de duas águas, algumas vezes caiada. O chão era de terra batida e os móveis escassos (Carvalho, 1940). Uma grande quantidade de símbolos e figuras povoavam o mundo do caiçara, no qual as imagens assumiam importância considerável (Setti, 1985).

Na cidade ou vila estavam concentradas as construções que representavam as instituições, a economia e a sociedade global: o porto, o mercado, a Igreja Matriz, as moradas do poder local e intermediários do poder externo, um pasto comum para abrigar as tropas que chegavam, poucas casas de artesãos e comerciantes, entre outras (Marcílio, 1986). A presença da Igreja Católica, principalmente no litoral norte de São Paulo, garantiu uma certa ligação entre as comunidades semi-isoladas e a cidade 9 . De forma geral, o caiçara era católico, mas não "no sentido rigoroso do cumprimento das obrigações e preceitos" (Langowiski, s.d.: 84). O 
Revista de Antropologia, São Paulo, USP, 2000, v. 43 nº 1.

casamento legal e religioso, na primeira metade do século XX, não era comum a toda a população. De fato, as uniões consensuais estáveis eram fenômeno comum entre os roceiros pobres. A festa de casamento era um dos momentos máximos na vida do caiçara e da coletividade rural. A morte era tida como fenômeno inexorável e natural e o funeral era um momento privilegiado de coesão da comunidade (Marcílio, 1986).

Para as populações caiçaras, as formas de lazer e distração eram as festas, procissões, danças, poucos jogos e os pasquins, espécie de literatura de cordel, que relatavam a vida nas comunidades ${ }^{10}$. Seu folclore era bastante rico (Diegues, 1983; Begossi, 1995 b). Os momentos de trabalho coletivo eram também importantes fatores de integração social da comunidade: mutirões de derrubadas, de queimadas e as "campanhas" de pesca de tainha (Marcílio, ibid.). Mas a proliferação de igrejas protestantes teve reflexo no folclore caiçara, e a quebra dos valores religiosos provocou o surgimento de conflitos em algumas comunidades (Diegues, ibid.).

O esquema geral de ocupação do litoral, que alternou períodos de prosperidade econômica com períodos de estagnação, foi descrito por vários autores para os Estados do Paraná ${ }^{11}$, São Paulo ${ }^{12}$ e Rio de Janeiro (Siqueira, 1989 b). Mourão (1971) observa que, de forma geral e até meados do século XX, durante os períodos de prosperidade em que outras alternativas econômicas eram oferecidas aos caiçaras, suas atividades tradicionais eram abandonadas em favor daquelas, e muitas vezes houve um aumento da população urbana nos municípios do litoral. Por outro lado, nos períodos de estagnação, normalmente, o caiçara voltava às suas atividades tradicionais, como forma de garantir sua subsistência, havendo um retorno para a área rural. Após a abertura das estradas de acesso ao litoral norte do Estado de São Paulo, na segunda metade do século XX, as transformações sócio-econômicas, que até então ocorriam lentamente, passaram a ocorrer de modo acelerado, com a chegada do turismo e da urbanização do litoral. A paisagem rural foi se transformando numa paisagem urbana e o caiçara foi sendo expulso para as cidades (Vitae Civilis, 1995; Luchiari, s.d.). 
Pretende-se argumentar aqui que muitas das concepções atualmente vigentes sobre a cultura caiçara na literatura foram criadas com base nos primeiros autores que publicaram sobre estas comunidades ${ }^{13}$, que as descreveram, justamente, num desses períodos históricos de estagnação econômica, criando a idéia de uma sociedade caiçara "tradicional", "primitiva", "isolada"e "auto-suficiente", utilizada pela maioria dos estudos subseqüentes.

\section{Lavradores ou pescadores?}

Diversas descrições sobre o "antigo" modo de vida caiçara (França, 1954; Mussolini, 1980; Cunha \& Rougeulle, 1989) demonstram a importância da agricultura na economia e na sobrevivência das comunidades ${ }^{14}$. Entretanto, trabalhos mais recentes, invariavelmente, referem-se ao caiçara como pescador, que depende de sua roça apenas de forma acessória e possui todo um universo voltado para o mar, além de um domínio eficiente das técnicas de pesca e de manejo do ecossistema marítimo ${ }^{15}$, com pouquíssimas exceções (Sanches, 1997). Para Silva (1989: 42), às vezes, é "muito difícil classificar o pescador-lavrador como um agricultor que pesca, ou um pescador que planta, pois a tradição do trabalho agrícola e do trabalho na pesca são da mesma intensidade e regularidade". Concordamos com Gusmão, que afirma que:

O homem litorâneo é identificado como pescador, ou então, o chamado "caiçara" descaracterizado, isto é, não mais ligado às formas de vida e trabalho próprias do litoral... Além disso, a produção científica a respeito, não vem permitindo percepção adequada do momento atual e das transformações históricas ocorridas nas últimas décadas. (1979: 9)

Diversos autores discutem a definição de pescador artesanal ${ }^{16}$. Para Diegues (1983), a pesca realizada nos moldes da categoria de pequena produção mercantil é dividida entre pescadores-lavradores (cuja produção enquadra-se na noção de campesinato) e pescadores artesanais 
(que se aproximam mais da corporação de ofício). Para Maldonado (1986), dependendo da forma com que o meio marítimo seja explorado, surgem percepções específicas do significado do mar e do trabalho na pesca, que se traduzem em comportamentos distintos com relação à natureza. Para a autora (ibid.), o pescador-agricultor é aquele que pesca e planta para produzir e comercializar, praticando uma pesca simples, que o impede de alcançar longas distâncias no mar. A exploração da terra e do mar caracterizam um pluralismo econômico e a associação destas duas atividades garante sua subsistência em épocas pouco propícias à pesca.

Para Beck (1989) ${ }^{17}$, o que caracteriza as comunidades pescadoraslavradoras é a relação entre a pesca de pequena escala (ou artesanal) e a agricultura de pequena escala (ou familiar, camponesa), "sintetizada na dupla identidade auto-atribuída: lavradores e pescadores" (ibid.: 291). O lavrador domina o conhecimento da terra, dos ciclos anuais, das técnicas, dos períodos de chuva e seca e tem o controle do grupo familiar para o trabalho na roça e no engenho. O pescador é o que domina o conhecimento do mar e da pescaria. Esta articulação entre roça e pesca parece ter uma importância fundamental na organização da vida econômica, do universo simbólico e de toda a organização social do lavrador-pescador. Para Mussolini (1980), a inexistência de meios materiais que possibilitassem seu deslocamento para longe da costa, fazia com que a maior parte das comunidades caiçaras garantisse sua subsistência com a produção da roça, derrubando a Mata Atlântica, complementada pela pesca costeira ou pela caça.

Outros autores (Hoefle, 1989) discordam do enfoque dualista do pescador artesanal/pescador comercial. Bernardes \& Bernardes (1950) separam os processos de pesca em dois grupos, dependendo das técnicas utilizadas: a pesca interior, realizada em lagoas, embocaduras de rios e fundos de enseadas; e a pesca marítima ou costeira, que compreende tanto os processos tradicionais, como os modernos, utilizados nas praias, pontas, ilhas rochosas e ao largo da costa. Mesmo assim, todos os autores 
concordam que há uma clara distinção entre o mundo simbólico e a organização social e produtiva daqueles que dependem basicamente da agricultura e daqueles que dependem primordialmente da pesca.

A literatura publicada sobre populações caiçaras, a partir da década de 1970, tende a caracterizá-las como pescadoras tradicionais ou embarcadas, identificando-as com um mundo simbólico e tecnológico marítimo. Não se discute sua origem sob uma perspectiva histórica, diacrônica, deixando de considerar que os caiçaras pescadores artesanais e embarcados surgiram a partir dos lavradores-pescadores, e somente após as mudanças ocorridas entre as décadas de 1930-50, período relativamente recente. Em nossa visão, as populações caiçaras eram constituídas, no passado, primordialmente por lavradores-pescadores, com raras exceções em comunidades dependentes essencialmente da pesca. Após a introdução do cerco e do barco a motor, em meados do século XX, essas comunidades passaram a dedicar uma parte cada vez maior de seu tempo às atividades da pesca, em detrimento da lavoura. Como confirma Diegues (1983: 1), povos com grande tradição marítima aparecem apenas "em certas situações no Brasil, onde, salvo alguns casos, a tradição pesqueira marítima é reduzida ou em formação".

Sob este ponto de vista, a Baixada Santista tem um papel histórico primordial. A pobreza de seus solos, que nunca permitiu a expansão da atividade agrícola, e o desenvolvimento regional associados ao comércio e ao porto de Santos fizeram que surgissem, no início do século XX, condições para a formação precoce da pesca artesanal: a existência de um contingente de trabalhadores que conheciam as artes da pesca, que estavam liberados de outras atividades econômicas, e a formação de um mercado consumidor para o pescado, representado pelas populações urbanas de Santos, São Vicente e São Paulo (Ribeiro Neto \& Oliveira,1989). Foi da cidade de Santos que partiram os primeiros barcos a motor com pescadores profissionais para outras regiões do litoral sul/sudeste, responsáveis, em parte, pelo abandono total ou parcial da agricultura de subsistência e pela migração de mão-de-obra para a pesca embarcada (Silva, 1975). 
Revista de Antropologia, São Paulo, USP, 2000, v. 43 nº 1.

Concordamos com a definição de Silva (1993), que distingue duas formas tradicionais de produção na pesca brasileira, entre o século XVII e início do XX: aquela dos pescadores-lavradores ou pescadores-sitiantes (caiçaras de São Paulo e caboclos da Amazônia) e aquela dos pescadores marítimos artesanais (jangadeiros do Ceará ou Pernambuco, ou pescadores de saveiros da Bahia). Para o autor (ibid.: 41), ao contrário da "visão idílica, romântica, em torno da 'comunidade rústica', 'tradicional', e 'isolada", as comunidades litorâneas (nos Estados de São Paulo e Pernambuco) eram mais complexas, dinâmicas e divididas internamente do que parece a primeira vista. As mudanças pelas quais passaram as comunidades de pescadores, após 1930, tiveram relação, entre outros motivos, com a motorização dos barcos e a pesca seletiva: "um verdadeiro divisor d'águas" (ibid.: 99), já que se tratou de uma ruptura com o sistema de valores anterior. Essa mudança fez surgir entre os caiçaras o que Mourão chamou de "ideologia da pesca", além de uma nova noção de trabalho:

Em vista disso, atualmente, os antigos caiçaras paulistas, hoje em parte convertidos em pescadores exclusivos, reordenam seu modo de vida e seu referencial cultural, os quais passam a se articular mais intensamente, ao contrário do passado, com o universo marítimo. (1971 apud Silva, 1993: 134) ${ }^{18}$

Assim o surgimento do barco a motor promoveu toda uma mudança no modo de vida caiçara, inclusive na importância da roça para sua subsistência. Em alguns casos, o caiçara passou a dedicar um tempo maior às atividades da pesca, em outros houve um abandono completo das atividades agrícolas. A chegada do barco a motor é descrita por diversos autores em diferentes comunidades caiçaras. Mourão (1971) faz uma bela análise da passagem da economia agrária para a pesca artesanal motorizada no município de Cananéia (SP). Carvalho (1940) destaca que a pesca de alto mar não era utilizada pelo praiano do litoral norte de São Paulo por falta de tecnologia adequada (barcos) e era praticada apenas pelos barcos vindos de Santos. No litoral do Rio de Janeiro, em meados do século XX, o principal processo de pesca ao largo era o da pesca de 
traineira, introduzida em 1930 (Bernardes \& Bernardes, 1950). A fase da pesca costeira comercial na Ilha de São Sebastião (SP) vai causar o quase completo abandono da agricultura em muitas partes da Ilha e a formação de povoados de pescadores vindos de diversas partes, atraídos pelo barco a motor e pelo cerco flutuante (introduzido provavelmente em 1920) ${ }^{19}$ (França, 1954). Silva (1979) discute o aumento da importância da pesca em relação às atividades agrícolas em Trindade (RJ), por volta de 192030. Diegues \& Nogara (1994) também discutem a troca da atividade combinada de agricultura e pesca de subsistência pela pesca embarcada, no Saco do Mamanguá (Parati-RJ), principalmente a partir dos anos 1940-50. A pesca embarcada é considerada como um "dos processos sócio-econômicos envolvidos na mudança social", que "passaram a alterar seu modo de vida tradicional" (ibid.:12). E ainda "nesse sentido, a pesca começou a substituir as atividades agrícolas até então predominantes em Parati" (ibid.: 24). No litoral sul de São Paulo, as comunidades caiçaras voltam-se para a pesca artesanal somente a partir de 1910 (Sanches, 1997).

Nem todos os lavradores-pescadores, porém, adaptaram-se bem às mudanças introduzidas pelo barco a motor. Em algumas vilas do litoral paranaense, constatou-se que recém-pescadores, de família agricultora, não se integraram completamente ao mundo marítimo (Rougeulle, 1989). De fato, algumas comunidades nunca fizeram essa transição, como Mandira, no litoral sul de São Paulo. A disponibilidade de um grande número de recursos naturais, graças às características naturais da região, parece ter possibilitado ao caiçara-lavrador permanecer nesta condição sem precisar se transformar em pescador artesanal para garantir sua sobrevivência (Sales \& Moreira, 1994).

Todavia, a maior parte dos autores considera que o caiçara é aquele que "tira do oceano seu principal sustento e o conhecimento profundo do oceano é motivo de orgulho" (Siqueira, 1989 a: 266). A nosso ver, essa generalização leva a algumas suposições incorretas, como as de que: o universo do caiçara é essencialmente marítimo; os caiçaras acumulam um conhecimento profundo do meio marítimo e de técnicas de manejo, 
herdadas de forma tradicional, que garantem o uso sustentado de seus recursos; as atividades agrícolas (roças) não produziram grande impacto na Mata Atlântica, desconsiderando a importância que estas atividades tiveram no passado.

Mesmo que hoje a realidade econômica do caiçara esteja primordialmente na pesca (e no turismo), parece difícil supor que em cerca de duas gerações, desde o surgimento do barco a motor, possa ter havido um acúmulo de conhecimento tão vasto sobre um meio cujo domínio, no passado, era principalmente costeiro, "transferido de pai para filho e guardado cuidadosamente pelos pescadores" (Diegues, 1993). Nesse sentido, acreditamos que características importantes, e que definem as comunidades caiçaras como agrícolas, mais próximas ao caipira paulista, na definição de Cândido (1964), não estão recebendo a consideração necessária na literatura. As análises de caráter sincrônico não consideram as mudanças e transformações históricas, mesmo as mais recentes, reduzindo a riqueza cultural dessas populações.

\section{"Isolamento" e a dependência da agricultura}

A passagem do lavrador-pescador para pescador quase que exclusivo (embarcado ou na sua praia de origem), modificou sua relação com a mata, como pode ser observado na Vila do Aventureiro ${ }^{20}$, onde apenas os homens mais velhos ainda dedicam-se exclusivamente à atividade agrícola e a maior parte do trabalho nas roças das famílias mais jovens é realizado pelas mulheres. Essa mudança, aliada à migração de contingentes populacionais para os centros urbanos, resultou na redução da área plantada e, conseqüentemente, contribuiu para a retomada das antigas roças pela capoeira, alterando os limites alcançados pela agricultura tradicional no passado, como já observava França (1954), na Ilha de São Sebastião.

Contudo, o isolamento a que essas comunidades estiveram submetidas, antes da chegada do barco a motor e das estradas ${ }^{21}$, sempre foi muito relativo e esteve relacionado, principalmente, a períodos de decadência 
econômica. A idéia de que as populações caiçaras só começaram a sofrer alterações significativas em seu modo de vida a partir de meados deste século é contestada por poucos autores ${ }^{22}$, o que tem contribuído para a vinculação do mito do "bom selvagem" a essas populações, o que parece ser uma influência da perspectiva neofuncionalista e diacrônica, reinante na Ecologia Cultural da década de 1970 (Headland, 1997).

Mourão (1971) faz a melhor descrição da alternância de ciclos econômicos e da relatividade do "isolamento" a que essas comunidades estiveram submetidas. Para o autor (ibid.), é só a partir da introdução do motor de centro (1960-68) nas canoas que começa a se caracterizar a emergência de uma ideologia da pesca, em parte da população. A tradição, passada de pai para filho, não existiu nesta época. A nova percepção do meio ambiente incorporou-se, aos poucos, à mentalidade dos pescadores artesanais motorizados (que adotaram técnicas difundidas por pescadores catarinenses). Essa passagem levou uma parte dos caiçaras a “...desenvolver toda uma tecnologia, em alguns casos completamente nova, para dominar o meio ambiente no qual vão buscar condições de subsistência” (ibid.: 205)

Entretanto, a população local sempre viveu sob a influência dos ciclos econômicos e a agricultura não escapou dessa realidade. Mourão (ibid.) aponta que a atividade agrícola, na região de Cananéia, deve ter sido um meio de garantir a sobrevivência ante a decadência cíclica de outras fontes: ouro, madeira, peixe, palmito e caixeta ${ }^{23}$. Nesse sentido, o autor discorda da dicotomia simplista que considera que a fase agrícola do caiçara corresponde a uma situação de "equilíbrio", de homogeneidade de comportamento, possível por uma situação de "isolamento" mais ou menos geral, tanto em termos geográficos como culturais; em oposição à fase da pesca, uma situação de desorganização social, em razão do rompimento do "isolamento". O isolamento e a integração social/econômica não podem ser medidos em termos meramente geográficos, mas dependem da relação entre o sistema econômico local e o sistema econômico global. Ao invés de considerar que o processo ocorrido em Cananéia tenha levado 
Revista de Antropologia, São Paulo, USP, 2000, v. 43 nº 1.

à desorganização e à desintegração social da população, o autor (1971) prefere considerar que tenha ocorrido uma reorganização social.

Setti (1985) considera mais prudente analisar o caso caiçara como um isolamento geográfico relativo e temporário, levando em conta que este nem sempre impõe um isolamento cultural. Assim considerar o caiçara como pertencente a uma população supostamente homogênea, num espaço supostamente definido como seu, conhecedor do meio em que vive e habilitado a dominá-lo de acordo com seus próprios recursos (conhecimentos e técnicas tradicionalizadas durante séculos), nem sempre corresponde à realidade, como foi observado pela autora (ibid.) em Ubatuba.

Para Murrieta (1994), as comunidades camponesas estão integradas às economias de mercado e aos sistemas políticos nacionais e internacionais há muito tempo, negando que tenham permanecido isoladas da sociedade colonial ou nacional, com as quais estabeleceram uma interação dialética, com diferentes graus de envolvimento e dependência político-econômica. $\mathrm{O}$ autor (ibid.) observa este fenômeno entre as populações caboclas da Amazônia, e argumenta que a idéia de uma sociedade "tradicional", "isolada", dependente de atividades de subsistência, "auto-suficiente" e "primitiva", deve ter sido inspirada por um dos momentos históricos de menor integração com o mercado, ou pelo ponto de vista colonial e discriminatório disseminado pelas elites locais e nacionais. Estudos realizados em outros países também mostram que as populações tradicionais pescadoras estão em processo de constante mudança, influenciadas pelas sociedades regionais/nacionais (McCay, 1978). Beck (1989) considera que as atividades agrícola e pesqueira se articulam de forma diferenciada, dependendo das necessidades do momento histórico. Wolf (1982) propõe que se olhe o mundo como uma totalidade, um sistema, através de uma abordagem histórica, ao invés de uma soma de sociedades e culturas desconexas: "If there are connections everywhere, why do we persist in turning dynamic, interconnected phenomena into static, disconnected things?”(1982: 4). 
Acreditamos que a idéia de uma sociedade caiçara "tradicional", no sentido descrito por Murrieta (1994) para os caboclos, também foi criada num período de relativo afastamento do mercado, quando os autores "clássicos" 24 entraram em contato e pela primeira vez descreveram essas comunidades. De fato, nesta época, o litoral vivia um período de estagnação, o que deve ter influenciado a idealização das comunidades caiçaras. Os autores do segundo período, ao buscarem suas fontes nos "clássicos", não fizeram uma releitura adequada do material, considerando o momento histórico vivido pelas comunidades caiçaras.

\section{O referencial marítimo como justificativa conservacio- nista ou a falta de uma abordagem ecológica}

Além da não incorporação de aspectos histórico-regionais mais amplos, outro fator raramente considerado na literatura sobre populações caiçaras são as características ecológicas locais que diferenciam estas comunidades entre si. Poucos autores, entre os quais Gusmão, levantaram esta questão:

...a) o habitante da orla litorânea, cuja atividade econômica é (em decorrência do processo histórico de ocupação dessa faixa) vinculada essencialmente à pesca e complementada por agricultura incipiente em torno da cultura de mandioca e feijão, próxima à habitação; b) o habitante das matas das baixadas e dos contrafortes da serra, onde essa existe, geralmente ligados às atividades extrativas e agrícolas incipientes; c) o habitante dos terraços fluviais, que tem contato esporádico com o oceano e pratica uma agricultura de subsistência, ligada à mandioca $\mathrm{e}$ à banana. (1979: 10-1)

Algumas populações caiçaras dependeram fortemente da agricultura no passado, como aquelas observadas por França (1954), Sales \& Moreira (1994) e Sanches (1997). Outras tiveram a pesca como principal atividade, conforme observado por Bernardes \& Bernardes (1950), enquanto outras ainda mesclaram essas duas atividades com intensidades diversas. É 
precisamente esta plasticidade que deve ter garantido a sobrevivência dessas populações (Netting, 1993) ${ }^{25}$.

Apesar das semelhanças culturais, as diferentes comunidades dependem de forma diferenciada dos recursos do meio ambiente e com relação a este aspecto não podem ser consideradas de forma homogênea. Assim, à caracterização das populações caiçaras como "tradicionais", "isoladas", "auto-suficientes", "primitivas" e possuidoras de um "referencial simbólico marítimo", junta-se a falta de abordagens ecológicas sérias e embasamento empírico levando, muitas vezes, a considerações ao discurso ecológico romântico. Para Sanches, dois dos aspectos que fundamentam os pressupostos político-ambientais a favor da permanência de determinados grupos em áreas protegidas são:

... [o] conhecimento inerente de suas experiências ancestrais sobre a ecologia das espécies e tipos de tecnologia apropriada que lhes permitiram se adaptar e reproduzir-se cultural e materialmente;... pela existência de uma relação de equilíbrio entre as práticas de manejo e o meio ambiente e de mecanismos culturais conservacionistas que impediriam a depleção dos recursos naturais em níveis comprometedores à manutenção dos mesmos. As populações tradicionais seriam, portanto, responsáveis inclusive pela preservação da biodiversidade.(1997: 27)

Nesse sentido, Diegues (1988: 3) objetiva "mostrar como a manutenção das culturas tradicionais ao longo da costa brasileira é uma das condições mais importantes para a preservação da diversidade biológica" sem, entretanto, acrescentar dados que permitam afirmar com segurança que "ao longo do litoral brasileiro existem muitas crenças e valores culturais que têm função de conservação" (ibid.: 6). Baseado em apenas três trabalhos sobre manejo de pesca realizados no litoral brasileiro (mas não com populações caiçaras) ${ }^{26}$, acredita que:

Pode-se afirmar, portanto, que a diversidade ecológica, em muitos casos, foi mantida por causa da diversidade cultural e das técnicas 
existentes nas comunidades de jangadeiros, caiçaras, povos indígenas, etc. (1988: 8)

Cunha \& Rougeulle, à parte o fato de salientarem que se trata de um trabalho preliminar, fazem afirmações conservacionistas de cunho cultural que carecem de confirmação de base biológica ou ecológica:

Um exemplo concreto é de que a região de Guaraqueçaba apresenta, após séculos de ocupação pelas populações litorâneas, um grau de conservação dos seus ecossistemas incomparável com outras regiões do Paraná e do Brasil. (1989: 5)

Diegues \& Nogara, apesar de não haver realizado um levantamento etnotaxonômico com a população do Saco do Mamanguá (RJ), afirmam que:

... existe no local uma extensa taxonomia folk, segundo a qual os vegetais e os animais são classificados em categorias como forte e fraco, vivo e não vivo, de couro e escama, masculino e feminino, bom e mau para o consumo, visível e invisível, bicho e não bicho. (1994: 61)

Para Milanelo:

Essas comunidades, ao longo de sua história, manejam o seu patrimônio natural conferindo grande estado de conservação a ambientes costeiros... São conhecidas como zeladoras do equilíbrio ecológico e seu desaparecimento pode comprometer todo um imenso patrimônio natural. (1992: 1009 e 1111 apud Diegues, 1989).

Comunidades tradicionais possuem técnicas de manejo que podem contribuir na manutenção dos ecossistemas tropicais, como possivelmente ocorre no caso da agricultura itinerante (Adams, 1994). O conhecimento do meio pelo caiçara refere-se, principalmente, a formas de cultivo da terra (mandioca); proibições e usos de animais e plantas; classificação da natureza (etnotaxonomia) e tecnologias apropriadas (Begossi, 1995 b). Entretanto, não é possível afirmar que o manejo tradicional caiçara garanta 
a diversidade ecológica com base nos estudos até hoje realizados (Sanches, 1997). Raramente a questão demográfica foi considerada, por exemplo, com exceção de França (1954) e Marcílio (1986).

Mesmo assim, nos casos mais extremos, até a permanência de populações caiçaras no interior das unidades de conservação é justificada com base em formas de manejo do meio marítimo, supostamente conservacionista ${ }^{27}$. Consideramos importantíssimo relativizar a existência de manejos de pesca sofisticados entre os caiçaras, já que a rearticulação, provocada pelo barco a motor, ocorreu há cerca de duas gerações. Em tão pouco tempo essas populações poderiam ter desenvolvido manejos baseados num referencial marítimo, oriundo de um "profundo conhecimento" desse meio?

Conforme aponta Silva (1993), foi somente a partir das transformações e mudanças ocorridas com o caiçara pescador-lavrador que seu referencial cultural "único, indivisível, inseparável" (: 41), constituído pela terra e pelo mar, altera-se para outro, basicamente, marítimo. Essa mudança de referencial pode ter resultado em perdas, decorrentes de sua adaptação à nova conjuntura, inclusive nas formas de manejo e no conhecimento do ecossistema terrestre, conforme observado por Begossi et. al. (1993) em Búzios (SP) ${ }^{28}$. Parece mais razoável supor que essas populações possuem um maior ou menor domínio e conhecimento de alguns tipos de pesca e ecossistemas, dependendo inclusive de fatores históricos e geográficos, e não do meio marítimo como um todo. Para Vianna, as populações tradicionais são idealizadas por parte do movimento ambientalista e do poder público brasileiro, "permeada de referências que remetem a idéias que as associam a povos 'primitivos', 'harmônicos', 'simbióticos' e 'conservacionistas"” (1996: 116). Segundo Diegues:

Um aspecto relevante na definição de "culturas tradicionais" é a existência de sistemas de manejo dos recursos naturais marcados pelo respeito aos ciclos naturais, à sua exploração dentro da capacidade de recuperação das espécies de animais e plantas utilizadas. Esses sistemas tradicionais de manejo não são somente formas de exploração econômica dos recursos 
naturais mas revelam a existência de um complexo de conhecimentos adquiridos pela tradição herdada dos mais velhos, de mitos e simbologias que levam à manutenção e ao uso sustentado dos ecossistemas naturais. (1993: 47, grifos nossos)

E Ângelo sustenta que:

Tem se apontado o conhecimento e dependência que os pescadores artesanais possuem do ambiente, o que permitiu a reprodução sustentável dos recursos naturais. Os estudos constatam a compatibilização de formas de extrativismo cooperativo com técnicas patrimoniais e trabalho familiar (ou de mutirão de vizinhança) como alternativas que permitiriam a sustentação do ambiente. (1990: 62)

Cunha \& Rougeulle, ao referirem-se às características das comunidades de economia tradicional, na qual os caiçaras estão inseridos, citam como uma de suas características:

... um conhecimento profundo dos ecossistemas de que fazem parte, o que permite a sua produção e reprodução social no tempo, bem como a manutenção e conservação dos próprios recursos naturais de que dependem para sobreviver. (1989: 4 e 5 , grifos nossos)

A importância dada, na literatura, ao etnoconhecimento das populações caiçaras demonstra uma influência da etnobiologia, que para Murrieta é "a pedra angular dos movimentos neo-roussounianos (sic) do desenvolvimento sustentável nos trópicos" (1996: 12). Um grande conhecimento de espécies significa apenas que essas populações têm uma boa percepção do meio em que vivem, o que não basta para afirmar que garantam a conservação do meio. A utilização do etnoconhecimento dessas populações também demonstrou, muitas vezes, uma grande confusão entre o ético e o êmico (Vianna ${ }^{29}$ ). Além disso, em situações de instabilidade econômica e crescimento populacional, a tragédia dos comuns (Hardin, 1968) pode 
Revista de Antropologia, São Paulo, USP, 2000, v. 43 nº 1.

ocorrer, como aponta Sales (1988), através do uso predatório do gerival ${ }^{30}$. Segundo Sanches:

A adaptação, no sentido biológico, ao ambiente hostil da floresta tropical atlântica é uma consequiência inevitável do longo processo de interação entre as comunidades caiçaras e esse ecossistema, mas não necessariamente implicou ou implica em uma relação ecologicamente equilibrada e estável com o meio natural (Hames, 1983). Afirmar isso, pelo simples fato de serem encontradas comunidades caiçaras em áreas bem preservadas, pode levar a conclusões errôneas. (1997: 115)

Consideramos que o desaparecimento das populações caiçaras, como tais, dificilmente poderia comprometer seriamente os ecossistemas terrestres ou marinhos utilizados por elas, principalmente a Mata Atlântica. Se essas populações realmente viessem a desaparecer, ou a serem definitivamente removidas de suas áreas originais de ocupação, poderíamos esperar alterações na dinâmica de recomposição das florestas e na composição específica. Mas, certamente, a maior perda seria na diversidade cultural e na relação entre biodiversidade e sociodiversidade, e não somente na biodiversidade, como se afirma. Esse fato, entretanto, não justifica, de forma alguma, a grandeza dessa perda.

\section{Considerações finais}

Verificou-se que a produção científica nacional, no que se refere às populações caiçaras, tem uma abordagem primordialmente sócio-cultural e, muitas vezes, forte orientação político-ideológica (Adams, 1996). Freqüentemente, incorpora conceitos antigos ou incorretos da Biologia/ Ecologia/Ecologia Cultural, faz generalizações com pouca ou nenhuma base empírica, e considera as populações caiçaras sob o viés do "bom selvagem”. Observa-se, também, que a literatura ecológica internacional raramente foi incorporada pelos pesquisadores que trabalham com 
populações caiçaras ${ }^{31}$. Ou seja, ocorre entre os caiçaras o mesmo fenômeno observado por Murrieta (1994) na bibliografia sobre caboclos da Amazônia: apesar da importante contribuição de diversos trabalhos na caracterização dessas comunidades, muito pouco foi feito com relação à ecologia desses grupos. O caráter qualitativo da maior parte desses estudos tem impedido um diagnóstico mais acurado dos múltiplos efeitos das mudanças atuais nas comunidades caboclas:

The literature, already scarce concerning the Caboclos, suffers from a chronic absence of quantitative data about energy flow, diet, nutrition, epidemiological patterns, and demography. (1994: 19)

Consideramos que as abordagens ecológicas são especialmente importantes no estudo de sociedades de pequena escala, pois são capazes de descrever e quantificar a maior parte das estratégias (forageio, caça, cultivo, extração e pesca) que, juntamente com as atividades comerciais, formam sua estrutura econômica. Essa combinação de análises quantitativas e qualitativas está se tornando cada vez mais importante, graças à urgência em se entender os efeitos da integração dos sistemas indígenas e de camponeses tradicionais no sistema capitalista (id., ibid.).

A partir do final dos anos 70, as abordagens ecológicas na Antropologia começaram a passar por um grande processo de reavaliação e crítica. A obsessão calórica ou protéica, bem como a análise reducionista dos primeiros trabalhos ecológicos, tem sido abandonada em favor de uma análise mais holística, que leva em conta não apenas o meio ambiente local, mas também a integração dos sistemas locais na economia de mercado e contextos sócio-políticos mais abrangentes (Headland, 1997; Murrieta, 1994; Wolf, 1982). A idéia das populações tradicionais como conservacionistas naturais, que vivem em harmonia com seus ambientes, vem sendo revista desde a década de 1980 (Headland, ibid.), no exterior.

Nesse sentido, a Ecologia Histórica - uma das abordagens mais recentes da Antropologia Ecológica - parece ser uma das melhores ferramentas 
para compreender as culturas tradicionais etnográficas, e poderia dar grandes contribuições no caso dos caiçaras. A Ecologia Histórica estuda os sistemas ecológicos não só através de seus componentes humanos (economia, religião, política etc.), como também considera seu aspecto diacrônico. Ou seja, é através da história que se busca entender a estrutura e função do ecossistema, e a cultura de seus habitantes. A história, nesse contexto, significa mais do que o passado dos indivíduos, pois inclui a análise da dialética entre mudança ambiental e mudança cultural (Headland, 1997).

Mesmo assim, grande parte da comunidade científica nacional se manteve à margem das abordagens ecológicas na Amazônia (Neves, 1989) e na Mata Atlântica, pelo menos até muito recentemente (Sanches, 1997, e os diversos trabalhos de Begossi e sua equipe). Se no caso amazônico ainda há tempo para alcançar o atraso, na Mata Atlântica corre-se o risco de perder o objeto de pesquisa, tal a rapidez com que os últimos remanescentes florestais vêm sendo degradados. Esperamos, entretanto, que num futuro próximo esforços interdisciplinares de pesquisa venham possibilitar a formação de grupos voltados para o estudo da Antropologia Ecológica de nossas populações, incorporando a contribuição das áreas biológicas, sem a perda teórica da Antropologia.

\section{Notas}

1 Artigo baseado na dissertação de mestrado Caiçaras na Mata Atlântica: pesquisa científica versus planejamento e gestão ambiental, defendida no Curso de Pós-Graduação em Ciência Ambiental (PROCAM-USP) em 1996.

2 Nenhuma corrente de imigrantes estrangeiros estabeleceu-se no litoral de São Paulo, salvo tentativas fracassadas de colonização japonesa na Baixada do Ribeira e Itanhaém (Mussolini, 1980).

3 O conceito de cultura adotado pela autora (Ribeiro, 1987: 95) refere-se aos "modos [brasileiros] de produzir, interagir, pensar e simbolizar, desenvolvidos ou adotados para satisfazer as necessidades humanas". 
4 Mussolini (1955) cita alguns exemplos de elementos sócio-culturais que, apesar das diferenças regionais, permitem a existência de uma uniformidade em nossos meios rústicos: agricultura de coivara, mutirão, troca dia, adjutório, complexo cultural da farinha da mandioca, complexo cultural da pesca da tainha, compadrio, novenas e folias.

5 França (1954) e Setti (1985) observaram que muitas vezes a população caiçara utilizava formas do linguajar caipira. Para França (ibid.), o caiçara da Ilha de São Sebastião tinha em comum com o caboclo do interior a estatura mediana, tez morena, cabelos escuros e lisos e freqüente prega mongólica.

6 Vianna (1996) também discute a conceituação de caiçara.

7 No Estado de São Paulo restam, hoje em dia, algumas poucas comunidades que vivem ou em pontos semi-isolados pela falta de estradas (litoral sul do Estado) e ilhas, ou no Saco do Mamanguá e na Cajaíba, no litoral sul do Rio de Janeiro (Ângelo, 1990). Boa parte dessas comunidades está inserida nas diversas categorias de unidades de conservação, que protegem os remanescentes da mata atlântica e criaram sérios impedimentos à sua economia tradicional.

8 A faixa de terra entre a orla marítima e as encostas da serra, no litoral de São Paulo, é denominada de sertão e geralmente possui o mesmo nome da praia correspondente.

9 Bovy (1972) faz um levantamento da situação sócio-econômico-religiosa das comunidades de pescadores do litoral de São Paulo.

10 Ver Mussolini, G., Os pasquins do Litoral Norte de São Paulo e suas peculiaridades na Ilha de São Sebastião, São Paulo, ECA-USP, 1971, série Jornalismo.

11 IPARDES, 1989; Cunha \& Rougeulle, 1989; Langowiski, s.d.; Rougeulle, 1989.

12 França, 1954; Simão \& Goldman, 1958; Silva, 1975; Mussolini, 1980; Diegues, 1983; Winther et al., 1989; Silva, 1993. 
13 Almeida, 1945, 1946; Willems, 1946; Pierson \& Teixeira, 1947; Bernardes \& Bernardes, 1950; França, 1954; Schmidt, 1958; Mussolini, 1980.

14 Considerando a cultura caiçara como parte da cultura caipira, também Cândido (1964) destaca a importância da agricultura.

15 "A essência da pesca artesanal é o conjunto de conhecimentos sobre meioambiente, as condições de marés, a identificação dos pesqueiros, o manejo dos instrumentos de pesca. Este conjunto de conhecimentos faz parte dos meios de produção dos pescadores artesanais...em geral transferido de pai para filho e guardado cuidadosamente pelos pescadores, como provam vários estudos antropológicos e sociológicos realizados no Brasil recentemente" (Mourão, 1971; Diegues, 1983, 1993; Cordell, 1974; Maldonado, 1991).

16 Diegues, 1983; Maldonado, 1986; Silva, 1989; Hoefle, 1989; Beck, 1989.

17 Apesar de ter baseado sua definição em estudo de caso realizado numa comunidade pesqueira localizada ao norte da Ilha de Santa Catarina, a comunidade estudada possui características muito semelhantes às dos caiçaras aqui considerados.

18 Alguns anos mais tarde, a valorização dos terrenos dos caiçaras e a criação de unidades de conservação vão ser responsáveis por um profundo reordenamento no mundo caiçara.

19 Com eles determinou-se também o fim da canoa de voga - em 1929 já não existia mais nenhuma na rota para Santos (França, 1954).

20 Oliveira et al. (1994), Toffoli \& Oliveira (1996) e Oliveira et.al. (subm).

21 É certo, porém, que dessa vez as estradas para o litoral trouxeram consigo grandes mudanças, talvez irreversíveis, a sobrevivência caiçara baseada em atividades de subsistência, já que o território terrestre dessas populações está sendo vendido e ocupado por uma população eminentemente urbana, ou então resguardado sob a forma de unidades de conservação de uso restrito.

22 Dean, 1996; Mourão, 1971; Silva, 1993; Setti, 1985; Sanches, 1997. 
23 “A concentração da maior parte do tempo produtivo do caiçara naquele produto que apresentava melhores condições de mercado, em termos de procura, levou, aos poucos, a abandonar a roça de subsistência pois, inicialmente admitia que produzindo mais unidades de produto eleito pelo mercado, com o resultado da sua venda, teria condições de substituir uma série de produtos de uso diário" (Mourão, 1971: 103).

24 A literatura publicada sobre populações caiçaras pode ser dividida, grosso modo, em duas fases: uma compreende o período entre as décadas de 19301960 e a outra o período entre 1970-1995 (Adams, 1996). Os autores do primeiro período foram denominados de "clássicos" da literatura caiçara: Almeida (1945,1946), Bernardes \& Bernardes (1950), França (1954), Langowiski (s.d.), Mussolini (1980), Pierson \& Teixeira (1947), Schmidt (1958) e Willems (1946). De forma geral, estes trabalhos descrevem algumas das comunidades caiçaras que habitavam nosso litoral na primeira metade do século XX e enfocam aspectos históricos, culturais e econômicos (Begossi, 1995 a).

25 Inclusive atualmente, na medida em que estas comunidades permanecem mais ou menos dependentes da mata, da pesca e das atividades ligadas ao turismo.

26 Forman (1970), um dos trabalhos mais citados por Diegues (1988), recebeu várias críticas na literatura internacional durante a década de 1970 (McCay, 1978; Cordell, 1978; Orlove, 1980), inclusive quanto à sua tendência neofuncionalista ao afirmar, sem embasamento suficiente, que o segredo guardado sobre os pontos de pesca serve para reduzir a competição e prevenir a sobrepesca (Orlove, 1980).

27 Gostaria de deixar bem claro que sou favorável à manutenção dessas populações no interior das unidades de conservação da Mata Atlântica, por motivos que vão desde a manutenção da diversidade sócio-cultural até os direitos adquiridos. Mas, visando um manejo adequado da área, cada caso deve ser muito bem estudado sob uma perspectiva interdisciplinar, levando em consideração o grau de dependência que cada comunidade possui hoje do mercado regional/nacional, e portanto o quanto elas ainda dependem de suas atividades tradicionais de subsistência e das áreas de cultivo (inclusive em relação ao território). Além disso, a questão demográfica deve ser seriamente considerada, pois influi diretamente no impacto causado sobre os ecossistemas. 
Revista de Antropologia, São Paulo, USP, 2000, v. 43 nº 1.

28 Apesar de a autora demonstrar, em outras publicações, a riqueza do conhecimento caiçara: Begossi 1995 a, 1995 b, Begossi \& Figueiredo, 1995.

29 VIANNA, L. P. Comunicação pessoal, 1996, Universidade de São Paulo.

30 Um tipo de tarrafa, criado há menos de uma década em Paranaguá (PR).

31 Esta situação evidencia-se, por exemplo, pelo fato de haver poucos trabalhos publicados sobre populações caiçaras em revistas com arbitragem por referees anônimos, inclusive no exterior. Dos 180 trabalhos compilados, há três teses defendidas no exterior $(1,7 \%), 14$ trabalhos publicados em periódicos internacionais ou capítulos de livros (10\%) e nove trabalhos em anais de congressos internacionais $(3,3 \%)$. Entre estes destacam-se a Ecologia Humana e a Etnobiologia, com dez trabalhos cada, sendo a maioria recente (a partir de 1989) (Adams, 1996).

32 Programa de Pesquisa e Conservação de Áreas Úmidas no Brasil - Universidade de São Paulo.

33 Fundação Édison Vieira, Curitiba-PR.

34 Centro Nacional de Desenvolvimento Sustentável de Populações Tradicionais.

35 Fundação Florestal e Coordenadoria de Planejamento Ambiental da Secretaria de Estado do Meio Ambiente.

36 Instituto para o Desenvolvimento, Meio Ambiente e Paz.

\section{Agradecimentos}

À Fapesp (processo94/01608-0), pela bolsa de mestrado que deu origem a este trabalho. À prof ${ }^{a}$ Renate B. Viertler (FFLCH-USP) e ao prof. Walter A. Neves (IB-USP) pela orientação, e a Rui S. S. Murrieta (University of Colorado at Boulder) e Rosely A. Sanches (IB-USP) pelas leituras críticas e sugestões. 


\title{
Bibliografia
}

\author{
ADAMS, C. \\ 1994 "As florestas virgens manejadas”, Boletim Museu Paraense Emílio \\ Goeldi, vol. 10(1): 3-20, Série Antropologia. \\ 1996 Caiçaras na Mata Atlântica: pesquisa científica versus planejamento \\ e gestão ambiental, São Paulo, dissertação, Universidade de São \\ Paulo.
}

\begin{abstract}
ALMEIDA, A. P.
1945 "Usos e costumes praianos", Revista do Arquivo Municipal, n. 104: 67-80.

1946 "Da decadência do litoral paulista", Revista do Arquivo Municipal, vol. 12(107): 35-57.
\end{abstract}

\section{ÂNGELO, S.}

1990 "Picinguaba: três décadas numa vila de pescadores do litoral norte do Estado de São Paulo", Bol. Paul. Geografia, n. 69: 61-73.

BECK, A.

1989

Lavradores e pescadores: uma contribuição à discussão do conceito de pescador artesanal. In: ENCONTRO DE CIÊNCIAS SOCIAIS E O MAR, 3, 1989, São Paulo. Coletânea de Trabalhos Apresentados. São Paulo: PPCAUB/IOUSP/F.FORD/UICN, 1989. p. 289-94.

BEGOSSI, A.

1995 a "Fishing spots and sea tenure: incipient forms of local management in Atlantic Forest coastal communities", Human Ecology, v. 23 (3): 387406. 
1995 b "Cultural and ecological resilience among caiçaras of the Atlantic Forest coast and caboclos of the Amazon (Brazil)", in BERKES, F. \& FOLKE, C. (eds.), Linking social and ecological systems for resilience and sustainability, The Beijer International Institute of Ecological Economics.

BEGOSSI, A. \& FIGUEIREDO, J. L.

1995 "Ethnoichthyology of Southern Coastal Fishermen: cases from Buzios Island and Sepetiba Bay (Brazil)", Bull. Marine Science, vol. 5(2): 71017.

BEGOSSI, A., LEITÃO-FILHO, H. F., RICHERSON, P. J.

1993 "Plant uses in a Brazilian coastal fishing community (Búzios Island)", J. Ethnobiol., vol. 13(2): 233-56.

BERNARDES, S. \& BERNARDES,

1950 “A pesca no litoral do Rio de Janeiro", Revista Brasileira de Geografia, Rio de Janeiro, n. 2.

BOVY,L.

1972

O Pescador do litoral: um desconhecido? Estudo piloto da situação sócio-econômico-religiosa, São Paulo, Conselho Estadual de Cultura.

CÂNDIDO, A.

1964 Os parceiros do Rio Bonito. Estudos sobre o caipira paulista e a transformação dos seus meios de vida. 7 ed., São Paulo, Duas Cidades.

CARVALHO, M.C. V.

1940 O pescador no litoral do Estado de São Paulo. In: CONGRESSO BRASILEIRO DE GEOGRAFIA, 9, 1940, Florianópolis. Anais... Rio de Janeiro: Conselho Nacional de Geografia, 1940, vol. III. p. 680-88. 
Cristina Adams. As Populações Caiçaras e o Mito do Bom Selvagem

CORDELL, J.

1974 "The lunar tyde fishing cycle in Northeastern Brazil", Ethnology, vol. 13.

1978 "Carrying capacity analysis of fixed-territorial fishing", Ethnology, vol. 17: 1-24.

CUNHA, L. H. O. \& ROUGEULLE, M. D.

1989 Comunidades litorâneas e unidades de proteção ambiental: convivência e conflitos; o caso de Guaraqueçaba (Paraná), São Paulo, PPCAUB-USP ${ }^{32}$, estudo de caso $\mathrm{n}^{\circ} 2$.

DEAN, W.

1996 A ferro e fogo. A história e a devastação da Mata Atlântica brasileira, São Paulo, Companhia das Letras.

DIEGUES, A. C. S.

1983 Pescadores, camponeses e trabalhadores do mar, São Paulo, Ática.

1988 Diversidade biológica e culturas tradicionais litorâneas: o caso das comunidades caiçaras, São Paulo, NUPAUB-USP, Série Documentos e Relatórios de Pesquisa, n. 5.

1993 Realidades e falácias sobre pescadores artesanais, São Paulo, CEMAR-USP, série documentos e relatórios de pesquisa, n. 7 .

DIEGUES, A. C. S. \& NOGARA, P.

1994 O nosso lugar virou parque: estudo sócio-ambiental do Saco de Mamanguá - Parati - Rio de Janeiro, São Paulo, NUPAUB/CEMARUSP.

FORMAN, S.

1970

The raft fishermen. Tradition and change in the Brazilian peasant economy, Bloomington, Indiana University Press. 
Revista de Antropologia, São Paulo, USP, 2000, v. 43 nº 1.

FRANÇA, A.

1954 A Ilha de São Sebastião. Estudo de Geografia Humana, São Paulo, FFCL - USP, Boletim 178, Geografia, n. 10.

FUNDAÇÃO SOS MATA ATLÂNTICA

1992 Dossiê Mata Atlântica 1992, São Paulo.

GUSMÃO, N. M. M. de

1979 Campinho da independência: um caso de proletarização "caiçara". São Paulo, pp. 128, dissertação, Pontifícia Universidade Católica.

HARDIN, G.

1968 The tragedy of the commons, Science, vol. 162: 1243-48.

HEADLAND, T. N.

1997 "Revisionism in Ecological Anthropology”, Current Anthropology, vol. 38(4): 605-30.

HOEFLE, S. W.

1989

A pesca de pequena escala no Sudeste do Brasil: estratégias de capitalização frente à pesca empresarial e ao turismo no sul fluminense. In: ENCONTRO DE CIÊNCIAS SOCIAIS E O MAR, 3, 1989, São Paulo. Coletânea de Trabalhos Apresentados. São Paulo, PPCAUB/ IOUSP/F.FORD/UICN, 1989. p. 151-77.

IPARDES $^{33}$

1989

APA de Guaraqueçaba: caracterização sócio-econômica dos pescadores artesanais e pequenos produtores rurais, Curitiba, Convênio IPARDES/SEMA/MDUMA. 
Cristina Adams. As Populações Caiçaras e o Mito do Bom Selvagem

\section{LANGOWISKI, V. B. R.}

s.d. Contribuição para o estudo dos usos e costumes do praieiro do litoral de Paranaguá, xerox, pp. 77-101.

LUCHIARI, M. T. D.P.

s.d. A relação do homem com o meio ambiente no universo caiçara, xerox.

MALDONADO, S. C.

1986 Pescadores do mar, São Paulo, Ática, Série Princípios.

1991 Em dois meios, em dois mundos: a experiência pesqueira marítima, Brasília. tese, Universidade de Brasília.

MARCÍLIO, M.L.

1986 Caiçara: terra e população. Estudo de demografia histórica e da história social de Ubatuba, São Paulo, Edições Paulinas/CEDHAL.

MCCAY, B. J.

1978 "Systems ecology, people ecology, and the anthropology of fishing communities", Human Ecology, vol. 6(4): 397-422.

MILANELO, M.

1992 Comunidades tradicionais do Parque Estadual da Ilha do Cardoso e a ameaça do turismo emergente. In: CONGRESSO NACIONAL SOBRE ESSÊNCIAS NATIVAS, 2, 1992, São Paulo. Anais...São Paulo: 1992. p. 1109-17.

MOURÃO, F. A. A.

1971 Os pescadores do litoral sul de São Paulo. Um estudo de sociologia diferencial, São Paulo, tese, Universidade de São Paulo. 
MURRIETA, R. S. S.

1994 Diet and subsistence: changes in three caboclo populations on Marajó Island, Amazonia, Brazil, Boulder, pp. 120, Thesis (Master of Arts), University of Colorado.

1996

Food choice, nutrition and development: praxis and intervention in three peasant communities on Ituqui Island, Amazonia, Brazil, Boulder, Research Proposal, University of Colorado, pp. 34.

MUSSOLINI, G.

1955 Persistência e mudança em comunidades de folk. In: CONGRESSO INTERNACIONAL DE AMERICANISTAS, 31, 1955. Anhembi, $\mathrm{H}$. Baldus (org.), 1955. vol. 1, p. 345-53.

1980

Ensaios de antropologia indígena e caiçara, Rio de Janeiro, Paz e Terra.

NETTING, R. M.

1993

Smalholders, Householders, Stanford, Stanford Univesity Press.

NEVES, W. A.

1989

"Teorias de determinismo ecológico na Amazônia: um caso de marginalidade da comunidade científica nacional", in NEVES, W. A. (org.), Biologia e ecologia humana na Amazônia: avaliação e perspectiva, Belém, SCT/PR CNPq, Museu Paraense Emílio Goeldi, Col. Eduardo Galvão.

NOFFS, P.DA S.

1988 Os caiçaras de Toque-Toque Pequeno. Um estudo de mudança espacial, São Paulo, dissertação, Universidade de São Paulo.

OLIVEIRA, R. R. DE; CLEVERÁRIO JR., J.; DELAMONICA, P. SUBMETIDO.

"Captura e conservação de nutrientes em cinco estágios sucessionais de Mata Atlântica submetidos a roças caiçaras", Rev. Bras. Bot. 
Cristina Adams. As Populações Caiçaras e o Mito do Bom Selvagem

OLIVEIRA, R. R. de; LIMA, D. F.; SAMPAIO, P. D.; SILVA, R. F. da; TOFFOLI, D. G.

1994 “Roça caiçara: um sistema 'primitivo’ auto-sustentável”, Ciência Hoje, vol. 18(104): 44-51.

ORLOVE, B.S.

1980 "Ecological anthropology", Ann. Rev. Anthropol., vol. 9: 235-73.

PIERSON, D. \& TEIXEIRA, C. B.

1947 “'Survey’ de Icapara”, Sociologia, São Paulo, n. 9.

RIBEIRO, B. G.

1987 "O índio na cultura brasileira", Pequena Enciclopédia da Cultura Brasileira, Rio de Janeiro, Unibrade/UNESCO.

RIBEIRO NETO, F. B. \& OLIVEIRA, M. F. de

1989

Estratégias de sobrevivência de comunidades litorâneas em regiões ecologicamente degradadas: o caso da Baixada Santista, São Paulo, PPCAUB/F.FORD/IUCN/IOUSP, Série Estudos de Caso, n. 1.

\section{ROUGEULLE, M.D.}

1989 Pescas artesanais de Guaraqueçaba. In: ENCONTRO DE CIÊNCIAS SOCIAIS E O MAR, 3, 1989, São Paulo, Coletânea dos Trabalhos Apresentados. São Paulo, PCAUB/IOUSP/F.FORD/UICN, 1989. p. 281-88.

SALES, R. J.R.

1988 Aspectos da pesca artesanal na região lagunar de Iguape-Cananéia. In: ENCONTRO DE CIÊNCIAS SOCIAIS EO MAR, 2, 1988, São Paulo. Coletânea de Trabalhos Apresentados, São Paulo, NUPAUB-USP, Série Documentos e Relatórios de Pesquisa, 1988. p. 63-75. 
SALES, R. J. R. de \& MOREIRA, A. de C. C.

1994 Estudo de viabilidade de implantação de reservas extrativistas no Domínio Mata Atlântica, município de Cananéia, proposta de continuidade do projeto, São Paulo, NUPAUB/USP, CNPT ${ }^{34}$ /IBAMA, FF e CPLA ${ }^{35} /$ SMA.

SAMPAIO, T.

1987 O tupi na geografia nacional, Brasiliana.

SANCHES, R. A.

1997 Caiçaras e a Estação Ecológica de Juréia-Itatins (Litoral Sul - São Paulo), dissertação, Universidade de São Paulo.

SCHMIDT, C. B.

1958 A lavoura caiçara, Rio de Janeiro, Ministério da Agricultura, Serviço de Informação Agrária, Documentário da Vida Rural, n. 14.

SETTI, K.

1985 Ubatuba nos cantos das praias. Estudo do caiçara paulista e de sua produção musical, São Paulo, Ática.

SILVA, A.C. da

1975 O litoral norte do Estado de São Paulo. Formação de uma região periférica. São Paulo, IGEOG-USP, Série Teses e Monografias, n. 20.

SILVA, J. G. S. da

1993 Caiçaras e jangadeiros: cultura marítima e modernização no Brasil, São Paulo, CEMAR/USP. 
Cristina Adams. As Populações Caiçaras e o Mito do Bom Selvagem

SILVA, T.E. M. da

1989 Os pequenos pescadores, trabalhadores para o capital. In: ENCONTRO DE CIÊNCIAS SOCIAIS E O MAR, 3, 1989, São Paulo. Coletânea de Trabalhos Apresentados. São Paulo, PCAUB/IOUSP/F.FORD/UICN, 1989. p. 37-48.

SILVA, Y.M. de F. A. e

1979 Trindade: sobrevivência e expropriação, São Paulo, pp. 121, dissertação, Pontifícia Universidade Católica.

SIMÃO, A. \& GOLDMAN, F.

1958 Itanhaém. Estudo sobre o desenvolvimento econômico e social de uma comunidade litorânea, São Paulo, FFCL-USP, Boletim n. 226, Sociologia II, n. 1.

SIQUEIRA, P.

1989a Os caiçaras do Litoral Norte do Estado de São Paulo. In: ENCONTRO DE CIÊNCIAS SOCIAIS E O MAR, 3, 1989, São Paulo. Coletânea de Trabalhos Apresentados. São Paulo: PCAUB/IOUSP/F.FORD/UICN, 1989. p. 263-72.

1989 b Os caiçaras e a Rio-Santos, São Paulo em Perspectiva, vol. 3(4): 62-4.

TOFFOLI, D. D. G. \& OLIVEIRA, R. R.

1996 Aspectos agroecológicos de uma roça caiçara. In: SIMPÓSIO DE ETNOBIOLOGIA E ETNOECOLOGIA, 1, 1996, Feira de Santana.

VIANNA, L. P.

1996 Considerações críticas sobre a construção da idéia de população tradicional no contexto das unidades de conservação, São Paulo, pp. 217, dissertação, Universidade de São Paulo. 
Revista de Antropologia, São Paulo, USP, 2000, v. 43 nº 1.

\section{VITAECIVILIS ${ }^{36}$}

1995 Direito de uso de recursos naturais e de propriedade intelectual: $o$ caso Juréia, São Paulo, publicação interna.

WILLEMS, E.

1946 "Notas sobre as habitações temporárias de caiçaras", Sociologia, vol. 8(3): 216-7.

WINTHER, J., RODRIGUES, E. P. F. \& MARICONDI, M. I.

1989 Laudo de ocupação da comunidade de São Paulo, Bagre, Cananéia $(S P)$, São Paulo, PPCAUB/F.FORD/IUCN/IOUSP.

WOLF, E. R.

1982 Europe and the People Without History, Berkeley, University of California Press. 


\begin{abstract}
Characterisation of caiçara communities as traditional, isolated, self-sufficient, primitive, and with their subsistence based mainly on fishing is discussed based on a diachronic perspective. Transformations that occurred as a result of the arrival of the motor boat, in the beginning of the XX century, are stressed. The abandonment of agricultural activities, totally or partially, is analysed in a broader historical context, considering it as one of the innumerable economic cycles which these populations have already passed. The low number of ecological studies and appropriate field data are also criticised. It is argued that these communities are usually analysed in literature through an ecological romantic view, linking them to the "good savage" myth. It is also proposed that the lack of multidisciplinary studies reduces the cultural richness of these communities.
\end{abstract}

KEY-WORDS: caiçaras, ecological anthropology, indigenous populations, noble savage. 